\title{
Using Acetate Anions To Induce Translational Isomerization in a Neutral Urea-Based Molecular Switch**
}

\author{
Yi-Lin Huang, Wei-Chung Hung, Chien-Chen Lai, Yi-Hung Liu, Shie-Ming Peng, and \\ Sheng-Hsien Chiu*
}

Although the use of cations to switch interlocked machine-like systems between different states is quite common, ${ }^{[1]}$ reports of anion-mediated interlocked switches are rare. To the best of our knowledge, only a few examples of anion-controlled translational isomerism in interlocked molecular switches have been described: 1) the generation of a phenoxide anion on a rotaxane thread to attract Leigh's macrocycle ${ }^{[2]}$ and 2) exchange of the counteranions of ammonium ${ }^{[3]}$ or pyridinium ${ }^{[4]}$ ions to affect their interactions with complementary crown ether or naphthalene-derived recognition motifs. Because of their ability to act as strong Y-shaped

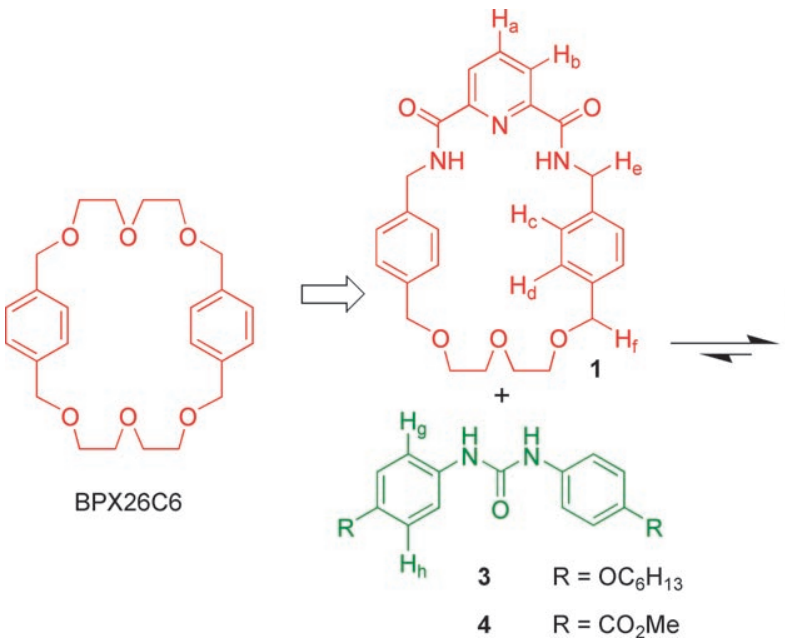

Scheme 1. Formation of a urea-based pseudorotaxane.

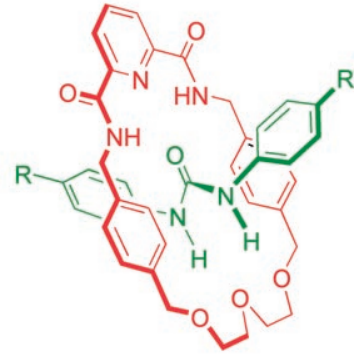

(1 $\supset$ 3) $\mathrm{R}=\mathrm{OC}_{6} \mathrm{H}_{13}$

(1 $\supset$ 4) $\quad \mathrm{R}=\mathrm{CO}_{2} \mathrm{Me}$ hydrogen-bond donors, urea and its derivatives play key roles in the design of receptors for anions, including both spherical halide anions and Y-shaped carboxylate anions, in solution. ${ }^{[5]}$ Conceptually, a [2]pseudorotaxane complex obtained after threading a urea-derived component through the cavity of a macrocycle should be a suitable system for constructing anion-controllable molecular switches because the recognition of anions by the urea recognition site would encourage relocation of the macrocycle to another recognition site. We are unaware, however, of any such switch having been reported to date. Herein, we report a new ditopic macrocyclic host that is capable of recognizing a dipheny-

[*] Y.-L. Huang, W.-C. Hung, Y.-H. Liu, Prof. S.-M. Peng, Prof. S.-H. Chiu Department of Chemistry

National Taiwan University

No. 1, Sec. 4, Roosevelt Road, Taipei, Taiwan

Fax: (+886) 2-3366-1677

E-mail: shchiu@ntu.edu.tw

Homepage: http://www.ch.ntu.edu.tw/english/efaculty/people/ chiu-eng.html

Prof. C.-C. Lai

Institute of Molecular Biology

National Chung Hsing University and

Department of Medical Genetics

China Medical University Hospital

Taichung, Taiwan

[**] This study was supported by National Taiwan University (95-R0061AN-00-01) and the National Science Council, Taiwan (NSC-952113M-002-016-MY3 and NSC-96-2752-M-002-006-PAE).

9 Supporting information for this article is available on the WWW under http://www.angewandte.org or from the author.

lurea-derived thread in a [2]pseudorotaxane fashion in solution. ${ }^{[6]}$ The controllable translational isomerism of its corresponding neutral [2] rotaxane was achieved through the addition and removal of acetate anions.

Previously, we reported that the diethylene glycol linkages in bis(para-xylyl)-[26]crown-6 (BPX26C6, Scheme 1) located its two xylene rings at a favorable $\pi$-stacking distance and, thus, helped its complexation to (mono)pyridinium and 4,4'bipyridinium ions in solution. ${ }^{[7]}$ Because 2,6-pyridinediamide is also an excellent spacer for locating aromatic rings at a suitable $\pi$-stacking distance, ${ }^{[8]}$ we designed the ditopic macrocycle $\mathbf{1}$, which possesses two xylyl rings linked by both diethylene glycol and 2,6-pyridinediamide spacers, as a host molecule capable of complexing diphenylurea derivatives. We expected that the corresponding [2]pseudorotaxane complexes (Scheme 1) would be stabilized through the cooperative effects of $\pi$ stacking (of the two xylyl rings about the planar $\pi$ system of the urea center) and $\mathrm{N}-\mathrm{H} \cdots \mathrm{O}$ hydrogen bonding (between the 2,6-pyridinediamide protons and the urea carbonyl oxygen atom and between the urea amide protons and the ethylene glycol oxygen atoms). ${ }^{[9]} \mathrm{We}$ obtained macrocycle $\mathbf{1}$ in $12 \%$ overall yield from the reaction of 4-bromomethylbenzonitrile with diethylene glycol under basic conditions (affording the bis(benzonitrile) 2), the $\mathrm{LiAlH}_{4}$-mediated reduction of $\mathbf{2}$, and subsequent macrocylization with dimethyl 2,6-pyridinedicarboxylate (Scheme 2).

To increase the solubility of diphenylurea in less-polar solvents (i.e., solvents that encourage hydrogen bonding between their solutes), we synthesized a diphenylurea deriv- 

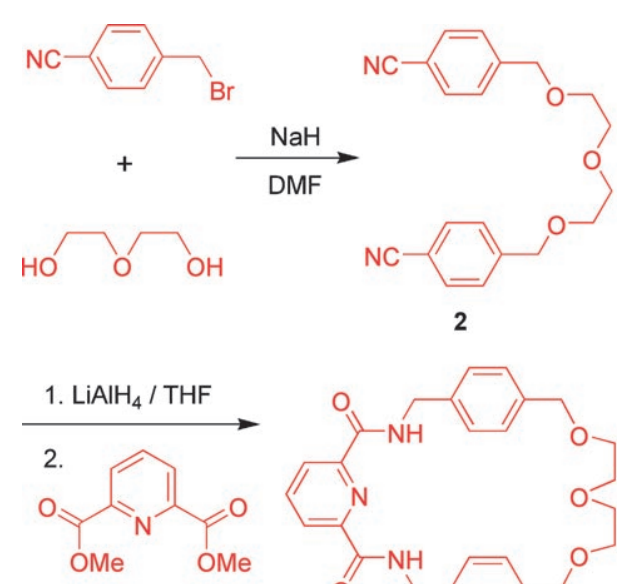

$12 \%$ in three steps

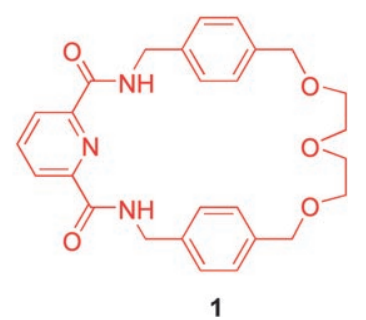

Scheme 2. Synthesis of macrocycle 1.

ative (3) with two hexyloxy side chains (see the Supporting Information). The ${ }^{1} \mathrm{H}$ NMR spectrum of an equimolar mixture of macrocycle $\mathbf{1}$ and the diphenylurea $\mathbf{3}$ in $\mathrm{CDCl}_{3}$ at room temperature displayed significant changes in the chemical shifts of the protons of the complex relative to those of its free components (see the Supporting Information). The separation of the originally overlapping signals for the protons of the two methylene groups in the diethylene glycol unit of macrocycle $\mathbf{1}(\delta=3.69 \mathrm{ppm})$ into two separate broad signals in the presence of the urea derivative $\mathbf{3}$ suggests that hydrogen bonding probably occurred between the host and guest. The broad, upfield-shifted signals of the protons of the xylyl groups of macrocycle $\mathbf{1}$ and of the phenyl groups of $\mathbf{3}$ in the mixture suggests the likelihood of stacking of the two components-such that the urea moiety is positioned within the cavity of the macrocycle, that is, in the form of a [2]pseudorotaxane assembly $\mathbf{1} \supset \mathbf{3}$ (Scheme 1). From a ${ }^{1} \mathrm{H}$ NMR spectroscopic dilution experiment, we determined the association constant $\left(K_{\mathrm{a}}\right)$ for the formation of this complex in $\mathrm{CDCl}_{3}$ to be $180 \mathrm{M}^{-1}$. ${ }^{[10]}$ Similar dilution experiments gave an association constant $\left(K_{\mathrm{a}}\right)$ for binding of the ester-substituted thread $\mathbf{4}$ to the macrocycle $\mathbf{1}$ as greater than $10^{4} \mathrm{M}^{-1},{ }^{[11]}$ which is more than 50 -fold higher than for the $\mathbf{1} \supset \mathbf{3}$ complexation. We suspect that this result is partly due to the electron-withdrawing ester substituents of $\mathbf{4}$ increasing the hydrogen-bond-donating ability of the $\mathrm{N}-\mathrm{H}$ bonds. ${ }^{[12]}$ Our hypothesis that this [2]pseudorotaxane was stabilized predominantly through hydrogen-bonding interactions between the two components is supported by our observation of only negligible shifts in the positions of the various signals in the ${ }^{1} \mathrm{H}$ NMR spectrum recorded from an equimolar mixture of $\mathbf{1}$ and 3 in $\mathrm{CD}_{3} \mathrm{CN}$ (i.e., a more-polar solvent). ${ }^{[13]}$

The ${ }^{1} \mathrm{H}$ NMR spectrum in Figure $1 \mathrm{~b}$ indicates that the addition of 2 equivalents of tetrabutylammonium acetate (TBAA) to an equimolar mixture of macrocycle $\mathbf{1}$ and the urea derivative $\mathbf{3}$ caused the reappearance of the signals of the free macrocycle and the appearance of signals of the complex formed between $\mathbf{3}$ and the acetate anion; that is, the addition of TBAA led to dissociation of the complex $\mathbf{1} \supset \mathbf{3}^{[12,14]}$ The
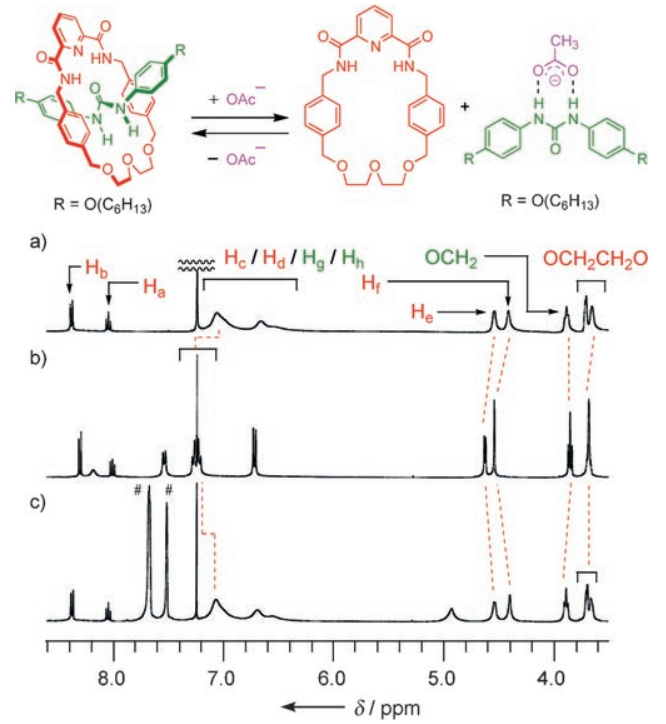

Figure 1. Partial ' $\mathrm{H}$ NMR spectra $\left(400 \mathrm{MHz} \mathrm{CDCl}_{3}, 298 \mathrm{~K}\right)$ of a) an equimolar mixture of 1 and $3(10 \mathrm{~mm}), b)$ the mixture obtained after adding TBAA (2 equiv) to the solution in (a), and c) the mixture obtained after adding $\mathrm{NaBAr}_{4}{ }_{4}$ (2 equiv) to the solution in (b). \#: Signals from $\mathrm{NaBAr}_{4}{ }_{4}$.

addition of 2 equivalents of sodium tetrakis[(3,5-bis(trifluoromethyl)phenyl]borate $\left(\mathrm{NaBAr}_{4}^{\mathrm{F}}\right)$ to the solution of macrocycle $\mathbf{1}$, urea derivative $\mathbf{3}$, and TBAA resulted in a ${ }^{1} \mathrm{H}$ NMR spectrum (Figure 1c) similar to that of the original mixture of $\mathbf{1}$ and $\mathbf{3}$ (Figure 1 a), suggesting that the original complex $\mathbf{1} \supset \mathbf{3}$ had been regenerated in solution as a result of the precipitation of sodium acetate. Thus, the sequential addition of TBAA and $\mathrm{NaBAr}^{\mathrm{F}}$ to a solution of $\mathbf{1}$ and $\mathbf{3}$ can be used to switch the complex between its non-associated and pseudorotaxane states; that is, this complex behaves as an acetate anion-controllable molecular switch.

To prove unambiguously that a [2]pseudorotaxane complex between macrocycle $\mathbf{1}$ and the diphenylurea $\mathbf{3}$ forms in solution, we attempted to stopper this complex to form a corresponding [2]rotaxane. Thus, we synthesized the [2]rotaxanes 6 and 7 (yields of isolated products: 23 and $20 \%$, respectively) through reactions of the semirotaxane formed between macrocycle $\mathbf{1}$ and the urea derivative $\mathbf{5}$ with two different bulky isocyanates (Scheme 3 ). ${ }^{[15]}$ For these rotaxanes, we expected that addition of an anion such as TBAA would cause the interlocked macrocycle to switch between the urea and carbamate recognition sites, that is, that $\mathbf{6}$ and $\mathbf{7}$ would function as molecular switches.

To confirm that the syntheses of molecular switches $\mathbf{6}$ and $\mathbf{7}$ resulted from recognition of the amide-based macrocycle $\mathbf{1}$ to the diphenylurea unit, rather than to the carbonyl group of the isocyanate motif, ${ }^{[16]}$ we synthesized the symmetrical rotaxane $\mathbf{9}$ from the reaction of $\mathbf{1}$, urea-derivative $\mathbf{8}$, and triisopropyl triflate (Scheme 4). ${ }^{[17]}$ We believe that the relatively low yield ( $12 \%$ ) of this reaction is due partially to the generation of anions during the reaction; these anions disrupt the hydrogen bonding of the remaining pseudorotaxane complexes. 


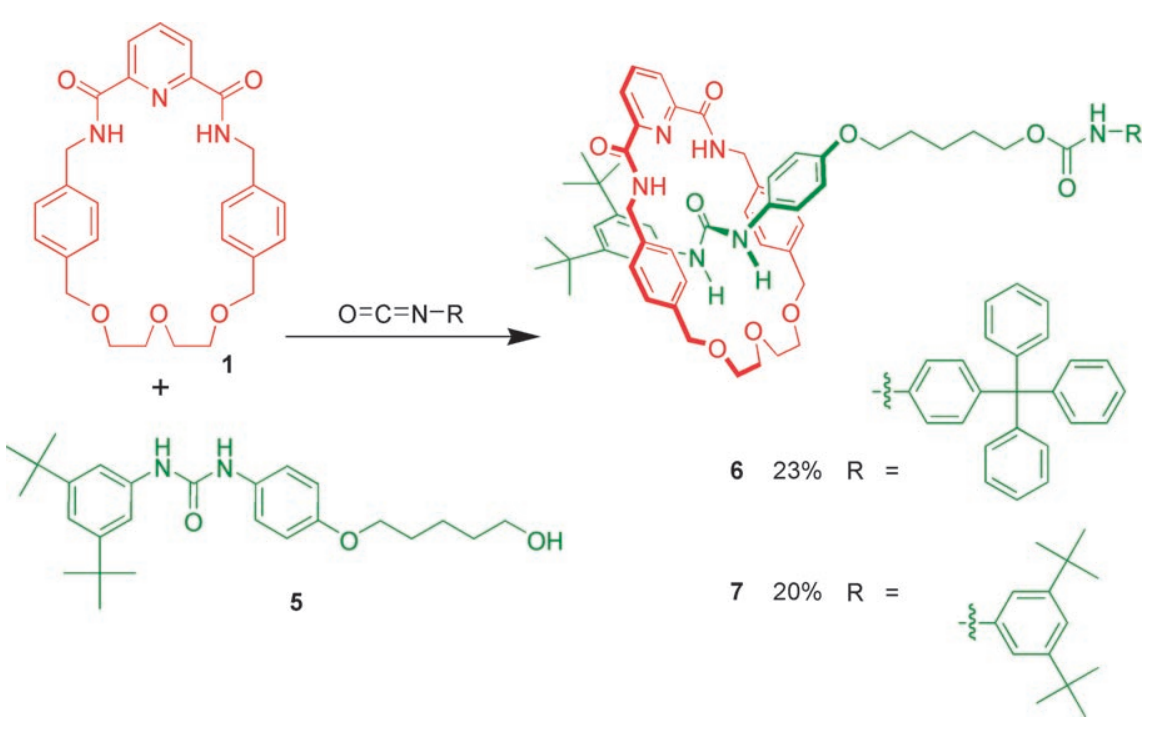

Scheme 3. Syntheses of molecular switches.

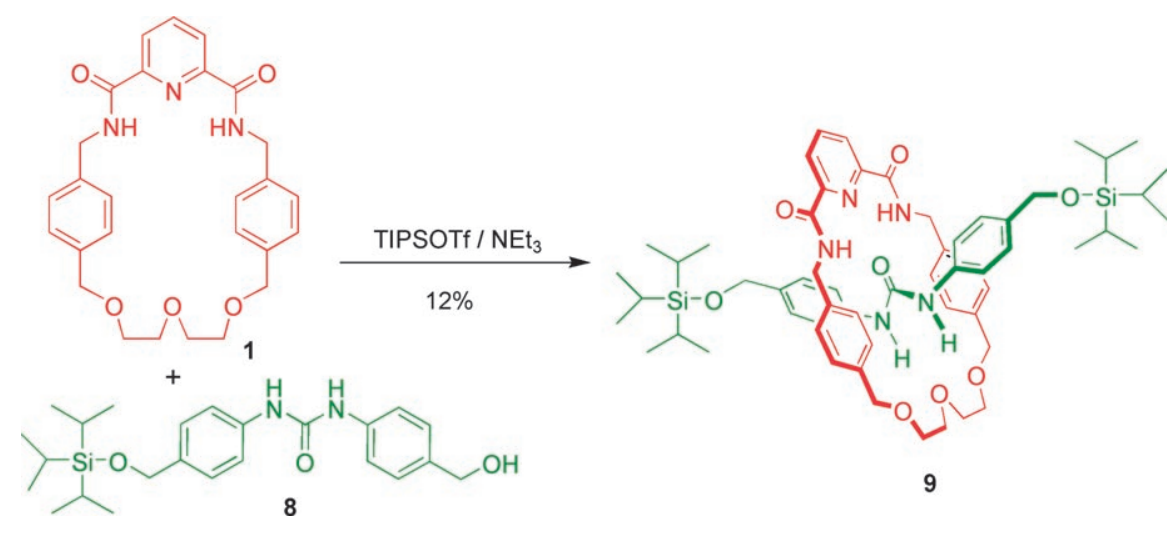

Scheme 4. Synthesis of a symmetrical [2]rotaxane.

We grew single crystals suitable for X-ray crystallography through liquid diffusion of hexane into a solution of rotaxane 6 in $\mathrm{CH}_{2} \mathrm{Cl}_{2}$. The solid-state structure ${ }^{[18,19]}$ (Figure 2) reveals the expected interlocked nature of the [2]rotaxane; macrocycle 1 resides on the diphenylurea unit with its two amide protons hydrogen bonded to the oxygen atom of the urea center. Interestingly, one water molecule acted as a hydrogen-

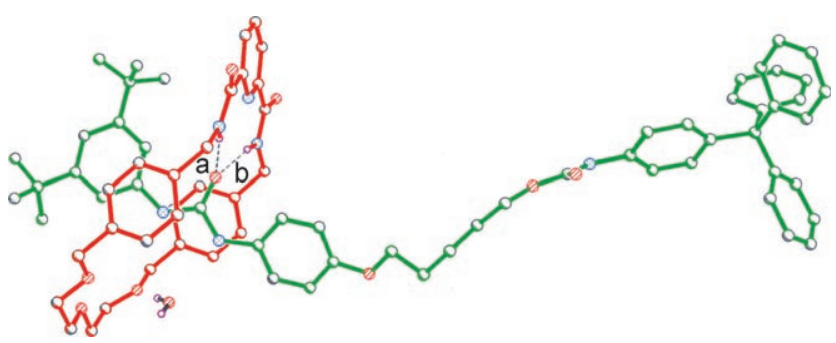

Figure 2. Ball-and-stick representation of the solid-state structure of [2]rotaxane 6. Atom labels: $\mathrm{C}$ gray, $\mathrm{H}$ pink, $\mathrm{O}$ orange, $\mathrm{N}$ blue. The hydrogen bonding geometries $\mathrm{X} \cdots \mathrm{O}, \mathrm{H} \cdots \mathrm{O}[\AA]$, and $\mathrm{X}-\mathrm{H} \cdots \mathrm{O}\left[{ }^{\circ}\right]$ are a) $2.88,2.05,164.6$; b) $2.91,2.08,161.7$. bonded bridge between the amide protons of the urea unit and the oxygen atoms of the diethylene glycol chain.

We employed [2] rotaxane 7 to demonstrate the acetate anion controllable switching behavior in solution while minimizing potential signal overlap in the aromatic region, which would complicate analysis of the spectra. 2D COSY and NOSY experiments helped us to identify most of the signals in the ${ }^{1} \mathrm{H}$ NMR spectrum of the [2]rotaxane 7 in $\mathrm{CDCl}_{3} / \mathrm{CD}_{3} \mathrm{CN}$ (1:1) at $298 \mathrm{~K}$ (Figure 3); we confirmed that, under these conditions, the macrocycle resided on the urea station (see the Supporting Information), as it did for $\mathbf{6}$ in the solid state (Figure 2). The addition of 5 equivalents of tetramethylammonium acetate (TMAA) to the [2]rotaxane 7 in $\mathrm{CDCl}_{3} / \mathrm{CD}_{3} \mathrm{CN}$ (1:1) induced significant changes in the ${ }^{1} \mathrm{H}$ NMR spectrum (Figure $3 b$ )—upfield shifts of protons $\mathrm{H}_{\mathrm{l}^{\prime}}$ and $\mathrm{H}_{\mathrm{j}^{\prime \prime}}$ and a downfield shift for proton $\mathrm{H}_{\mathrm{g}^{\prime}}$-after the addition of TMAA, suggesting that the macrocyclic component had moved from the urea station toward the carbamate station (Scheme 5). The 2D NOSY spectrum of this mixture displayed (see the Supporting Information) cross-signals of the xylyl protons $\left(\mathrm{H}_{\mathrm{c}^{\prime}}\right.$ and $\left.\mathrm{H}_{\mathrm{d}^{\prime}}\right)$ of the macrocycle and the amide protons of the

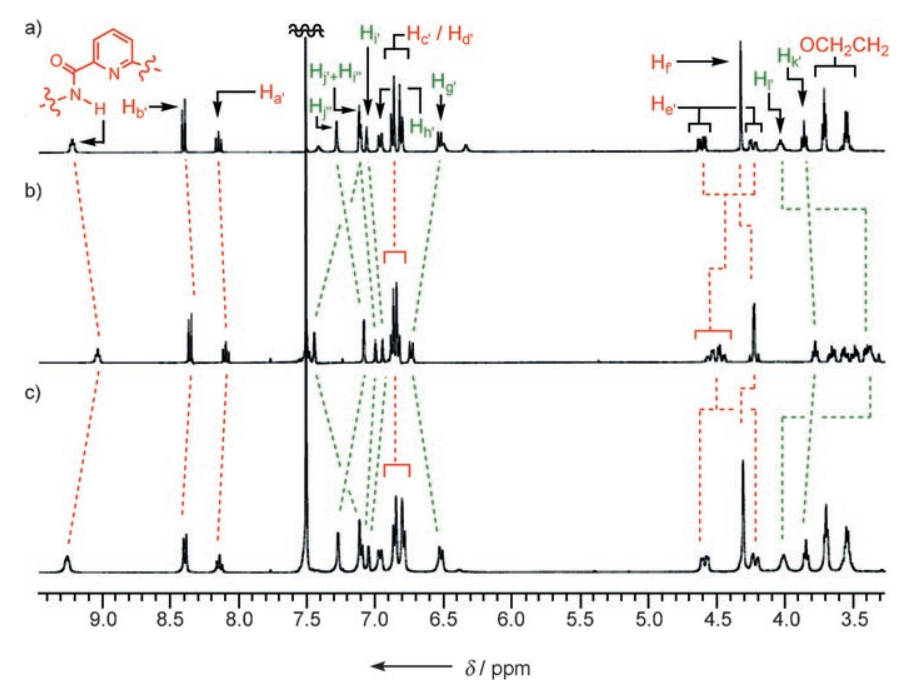

Figure 3. Partial ${ }^{1} \mathrm{H}$ NMR spectra $\left(400 \mathrm{MHz}, \mathrm{CDCl}_{3} / \mathrm{CD}_{3} \mathrm{CN}(1: 1)\right.$, $298 \mathrm{~K}$ ) of a) molecular switch 7, b) the mixture obtained after adding TMAA (5 equiv) to the solution in (a), and c) the mixture obtained after adding $\mathrm{NaClO}_{4}$ (5 equiv) to the solution in (b). 


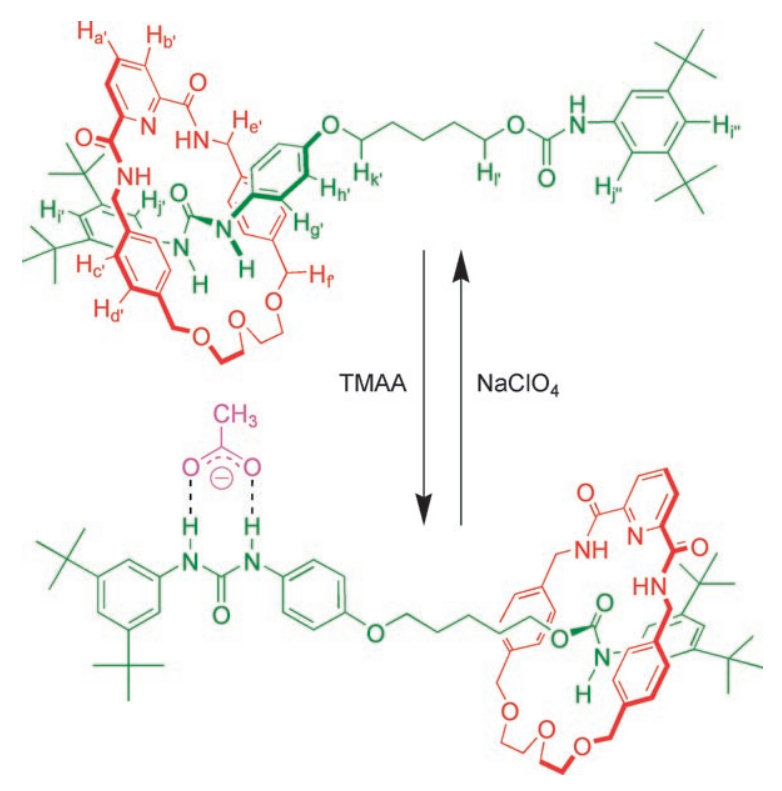

Scheme 5. Anion-controllable switching of molecular switch 7.

pyridine diamide to the aryl protons of carbamate terminus $\left(\mathrm{H}_{\mathrm{j}^{\prime \prime}}\right)$ and the protons adjacent to the carbamate motif $\left(\mathrm{H}_{\mathrm{l}^{\prime}}\right)$, confirming the encircling of the macrocyclic component about the carbamate moiety under these conditions. Thus, translocation of the interlocked macrocycle from the urea station to the carbamate station could be achieved by introducing an excess of acetate anions, which compete with the macrocyclic component for binding to the urea station. Subsequent addition of 5 equivalents of $\mathrm{NaClO}_{4}$ to this solution resulted in a ${ }^{1} \mathrm{H}$ NMR spectrum (Figure $3 \mathrm{c}$ ) similar to that of the original spectrum of [2]rotaxane 7 (Figure $3 \mathrm{a}$ ), suggesting that the macrocycle had returned to its preferred urea station, presumably because of precipitation of the acetate anion as $\mathrm{NaOAc}$ and the relatively weak interactions between the urea moiety and perchlorate anions under these conditions. ${ }^{[20]}$ Therefore, we could operate the translational isomerism of the interlocked molecular switch 7 reversibly through the sequential addition and removal of acetate anions (Scheme 5). Unlike previously reported systems, which required ion-pairing compounds to exchange the counteranions or the creation of negative charge (through deprotonation) on the molecular switch itself, we operated our [2]rotaxane-based molecular switch 7 through the competitive binding of external acetate anions to the urea recognition site, which allowed the [2]rotaxane to remain neutral throughout the switching process.

We have demonstrated that macrocycle 1 can form [2]pseudorotaxane complexes, stabilized through intermolecular hydrogen bonding, with diphenylurea derivatives in lowpolarity solvents. We exploited the fact that macrocycle $\mathbf{1}$ recognizes urea moieties to prepare a unique set of molecular switches that undergo anion-mediated switching, in which translational isomerism was achieved through competition between external acetate anions and the macrocyclic component for binding to the urea station. Because of the physiological importance of carboxylate anions and urea derivatives, it might be possible that this new molecular recognition system could be adapted for the preparation of biological detectors or sensors. Currently, we are studying electrochemically and photochemically controllable molecular switches based on this recognition system.

Received: May 18, 2007

Published online: July 30, 2007

Keywords: anion recognition - host-guest systems .

molecular switches rotaxanes $\cdot$ urea

[1] a) J.-P. Collin, C. Dietrich-Buchecker, P. Gaviña, M. C. JimenezMolero, J.-P. Sauvage, Acc. Chem. Res. 2001, 34, 477-487; b) G. Kaiser, T. Jarrosson, S. Otto, Y.-F. Ng, A. D. Bond, J. K. M. Sanders, Angew. Chem. 2004, 116, 1993-1996; Angew. Chem. Int. Ed. 2004, 43, 1959-1962; c) T. Iijima, S. A. Vignon, H.-R. Tseng, T. Jarrosson, J. K. M. Sanders, F. Marchioni, M. Venturi, E. Apostoli, V. Balzani, J. F. Stoddart, Chem. Eur. J. 2004, 10, 6375-6392; d) J. D. Badjić, V. Balzani, A. Credi, S. Silvi, J. F. Stoddart, Science 2004, 303, 1845-1849.

[2] C. M. Keaveney, D. A. Leigh, Angew. Chem. 2004, 116, $1242-$ 1244; Angew. Chem. Int. Ed. 2004, 43, $1222-1224$.

[3] a) M. Montalti, L. Prodi, Chem. Commun. 1998, 1461-1462; b) C.-F. Lin, C.-C. Lai, Y.-H. Liu, S.-M. Peng, S.-H. Chiu, Chem. Eur. J. 2007, 13, 4350-4355.

[4] B. W. Laursen, S. Nygaard, J. O. Jeppesen, J. F. Stoddart, Org. Lett. 2004, 6, 4167-4170.

[5] a) T. S. Snowden, E. V. Anslyn, Curr. Opin. Chem. Biol. 1999, 3, $740-746$; b) P. D. Beer, P. A. Gale, Angew. Chem. 2001, 113, 502-532; Angew. Chem. Int. Ed. 2001, 40, 486-516; c) R. Martínez-Máñez, F. Sancenón, Chem. Rev. 2003, 103, 44194476; d) B. Tomapatanaget, T. Tuntulani, J. A. Wisner, P. D. Beer, Tetrahedron Lett. 2004, 45, 663-666; e) V. Amendola, D. Esteban-Gómez, L. Fabbrizzi, M. Licchelli, Acc. Chem. Res. 2006, 39, 343-353; f) T. Gunnlaugsson, M. Glynn, G. M. Tocci, P. E. Kruger, F. M. Pfeffer, Coord. Chem. Rev. 2006, 250, $3094-$ 3117; g) P. A. Gale, R. Quesada, Coord. Chem. Rev. 2006, 250, 3219-3244; h) S. J. Brooks, S. E. García-Garrido, M. E. Light, P. A. Cole, P. A. Gale, Chem. Eur. J. 2007, 13, 3320-3329.

[6] Pseudorotaxane intermediates comprising urea-based threads and amide-based macrocycles have been proposed in elegant one-pot rotaxane syntheses from diisocyanates, a bulky aryl amine, and amide-based macrocycles. The true recognition system in this reaction, however, was not identified; the authors stated that "the mechanism of this rotaxane formation is yet not proven". See: O. Braun, F. Vögtle, Synlett 1997, 1184-1186.

[7] a) P.-N. Cheng, P.-Y. Huang, W.-S. Li, S.-H. Ueng, W.-C. Hung, Y.-H. Liu, C.-C. Lai, S.-M. Peng, I. Chao, S.-H. Chiu, J. Org. Chem. 2006, 71, 2373-2375; b) P.-N. Cheng, C.-F. Lin, Y.-H. Liu, C.-C. Lai, S.-M. Peng, S.-H. Chiu, Org. Lett. 2006, 8, 435-438.

[8] A. P. Bisson, V. M. Lynch, M.-K. C. Monahan, E. V. Anslyn, Angew. Chem. 1997, 109, 2345-2347; Angew. Chem. Int. Ed. Engl. 1997, 36, 2340-2342.

[9] Amide-based macrocycles have been used to construct many elegant interlocked molecules. In most circumstances, the threading of guests into these macrocycles required the cooperation of two or more suitably positioned carbonyl groups or anionic templates; see: a) G. A. Breault, C. A. Hunter, P. C. Mayers, Tetrahedron 1999, 55, 5265-5293; b) C. Reuter, W. Wienand, G. M. Hubner, C. Seel, F. Vögtle, Chem. Eur. J. 1999, 5, 2692-2697; c) J. A. Wisner, P. D. Beer, M. G. B. Drew, M. R. Sambrook, J. Am. Chem. Soc. 2002, 124, 12469-12476; d) M. R. Sambrook, P. D. Beer, J. A. Wisner, R. L. Paul, A. R. Cowley, J. Am. Chem. Soc. 2004, 126, 15364-15365; e) E. R. Kay, D. A. Leigh, Top. Curr. Chem. 2005, 262, 133-177; f) D. A. Leigh, 
A. R. Thomson, Org. Lett. 2006, 8, 5377-5379; g) J. Berna, G. Bottari, D. A. Leigh, E. M. Perez, Pure Appl. Chem. 2007, 79, $39-54$.

[10] K. A. Connors, Binding Constants, Wiley, New York, 1987; estimated error is $<30 \%$.

[11] We calculated the association constant from a ${ }^{1} \mathrm{H}$ NMR spectroscopic dilution experiment to be $11000 \mathrm{M}^{-1}$; we quote the value as $>10^{4} \mathrm{M}^{-1}$ because of the inherent error of this approach when the dissociation constant approaches the limit of detection of ${ }^{1} \mathrm{H}$ NMR spectroscopy.

[12] M. Boiocchi, L. Del Boca, D. Esteban-Gómez, L. Fabbrizzi, M. Licchelli, E. Monzani, J. Am. Chem. Soc. 2004, 126, 16507.

[13] For the influence of solvent on noncovalent interactions, see: C. A. Hunter, Angew. Chem. 2004, 116, 5424-5439; Angew. Chem. Int. Ed. 2004, 43, 5310-5324.

[14] For more details regarding the recognition of urea derivatives to acetate anions, see: a) M. P. Hughes, B. D. Smith, J. Org. Chem. 1997, 62, 4492-4499; b) R. J. Fitzmaurice, G. M. Kyne, D. Douheret, J. D. Kilburn, J. Chem. Soc. Perkin Trans. 1 2002, $841-864$.

[15] For more details regarding this stoppering method, see: a) Y. Furusho, H. Sasabe, D. Natsui, K. Murakawa, T. Takata, T.
Harada, Bull. Chem. Soc. Jpn. 2004, 77, 179-185; b) Y. Furusho, T. Matsuyama, T. Takata, T. Moriuchi, T. Hirao, Tetrahedron Lett. 2004, 45, $9593-9597$.

[16] According to reference [6], the amide-based macrocycle might also recognize isocyanates during the rotaxane synthesis.

[17] For more details about this stoppering method, see: E. Córdova, R. A. Bissell, N. Spencer, P. R. Ashton, J. F. Stoddart, A. E. Kaifer, J. Org. Chem. 1993, 58, 6550-6552.

[18] CCDC 647854 contains the supplementary crystallographic data for this paper. These data can be obtained free of charge from The Cambridge Crystallographic Data Centre via www.ccdc. cam.ac.uk/data_request/cif.

[19] Crystal data for 6: $\mathrm{C}_{79} \mathrm{H}_{86} \mathrm{O}_{9} \mathrm{~N}_{6} \cdot \mathrm{CH}_{2} \mathrm{Cl}_{2} \cdot \mathrm{H}_{2} \mathrm{O}, \quad M_{\mathrm{r}}=1366.48$, triclinic, space group $P \overline{1}, a=13.0119(4), b=14.1602(4), c=$ 20.4104(6) $\AA, \quad V=3662.43(19) \AA^{3}, \quad \rho_{\text {calcd }}=1.239 \mathrm{~g} \mathrm{~cm}^{-3}, \quad \mu$ $\left(\mathrm{Mo}_{\mathrm{K} \alpha}\right)=0.152 \mathrm{~mm}^{-1}, \quad T=295(2) \mathrm{K}$, colorless cubes; 12883 independent measured reflections, $F^{2}$ refinement, $R_{1}=0.0708$, $w R_{2}=0.1624$.

[20] The binding affinity of oxoanions toward urea derivatives is proportional to their basicity; see: V. Amendola, M. Bonizzoni, D. Esteban-Gómez, L. Fabbrizzi, M. Licchelli, F. Sancenón, A. Taglietti, Coord. Chem. Rev. 2006, 250, 1451-1470, and ref. [12]. 